\title{
Correction to: A probabilistic seismic hazard map for the metropolitan France
}

\author{
Stéphane Drouet ${ }^{1}$ D $\cdot$ Gabriele Ameri $^{3} \cdot$ Kristell Le Dortz $^{3} \cdot$ Ramon Secanell $^{1}$. \\ Gloria Senfaute ${ }^{2}$
}

Published online: 12 June 2020

(c) Springer Nature B.V. 2020

\section{Correction to: Bulletin of Earthquake Engineering (2020) 18:1865-1898 https://doi.org/10.1007/s10518-020-00790-7}

Figure 20 of Drouet et al. (2020) shows the mean PGA at 475 years of return period instead of the median PGA at 475 years of return period as written in the figure caption.

For clarity, the maps of mean and median PGA are presented below in Figs. 1 and 2.

The original article can be found online at https://doi.org/10.1007/s10518-020-00790-7.

Stéphane Drouet

s.drouet@fugro.com

1 FUGRO France, Auriol, France

2 EDF R\&D, Paris Saclay, France

3 SEISTER, Aubagne, France 


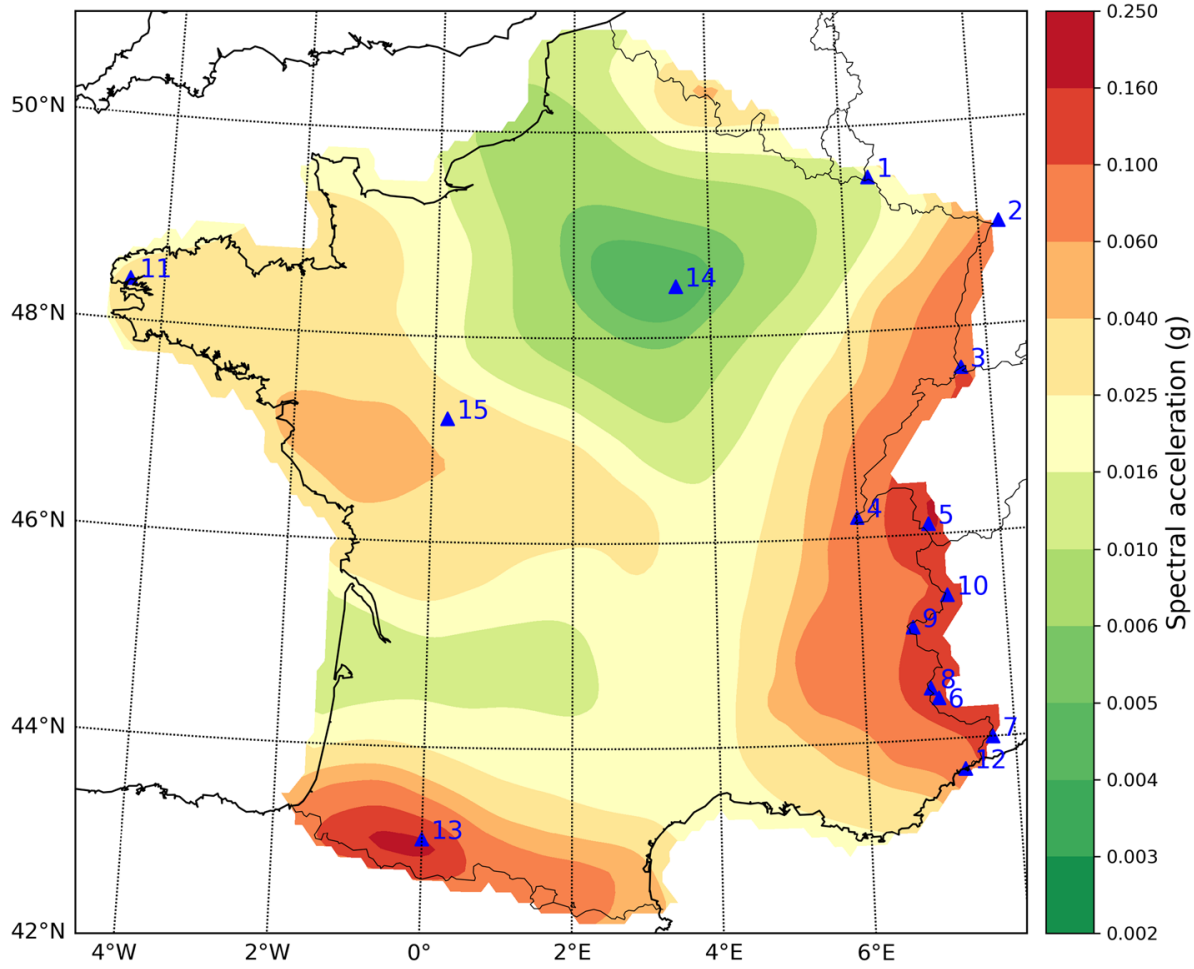

Fig. 1 Hazard map for mean PGA at 475 years return period (10\% probability of exceedance within 50 years). Blue triangles denote points where comparison with PSHA results from other studies are performed 


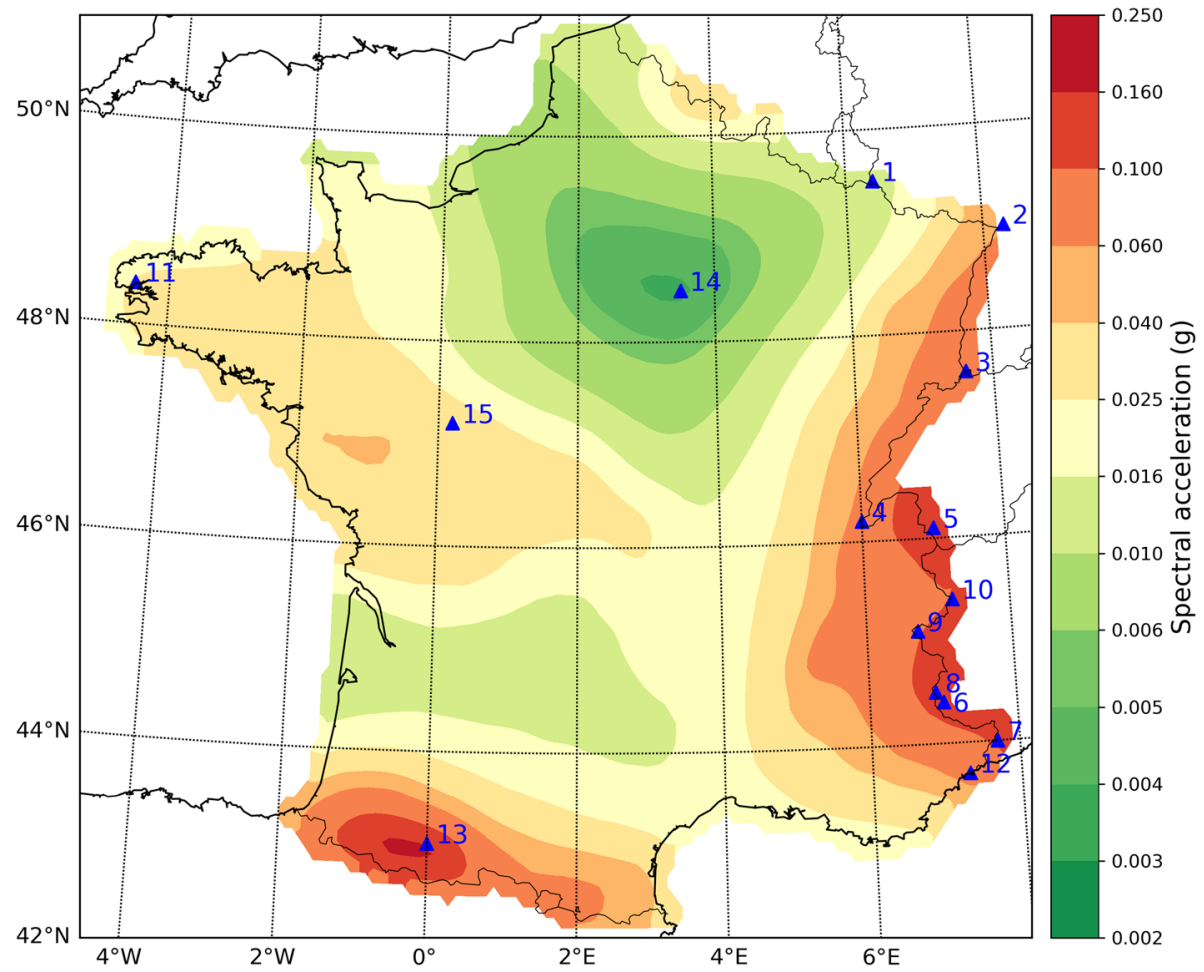

Fig. 2 Hazard map for median PGA at 475 years return period (10\% probability of exceedance within 50 years). Blue triangles denote points where comparison with PSHA results from other studies are performed

\section{Reference}

Drouet S, Ameri G, Le Dortz K, Secanell R, Senfaute G (2020) A probabilistic seismic hazard map for the metropolitan France. Bull Earthq Eng. https://doi.org/10.1007/s10518-020-00790-7

Publisher's Note Springer Nature remains neutral with regard to jurisdictional claims in published maps and institutional affiliations. 